\title{
EXISTENCE OF LOWER AND UPPER SOLUTIONS IN REVERSE ORDER WITH RESPECT TO A VARIABLE IN A MODEL OF ACIDOGENESIS TO ANAEROBIC DIGESTION
}

M.M. Higuera, Faculty of Natural Sciences and Mathematics, Research Group Naturatu, University of Ibague, Ibague-Tolima, Colombia; Faculty of Mathematics, University of Veracruz, Mexico, maximiliano.machado@unibague.edu.co,

A.V. Sinitsyn, Department of Mathematics, National University of Colombia, Bogota, Colombia, avsinitsyn@yahoo.com

We prove existence of upper and lower solutions in reverse order with respect a part of the variables in a system of nonlinear ordinary differential equations modelling acidogenesis in anaerobic digestion. The corresponding existence theorems are established. The upper and lower solutions are constructed analytically, by defining semi-trivial solutions for each of the variables in the model. We introduce the concept of indicator semi-trivial solutions. Finally, we numerically solve the system supported by the Matlab software and matching the graphs of the numerical solutions with analytical solutions is found.

Keywords: upper-lower solutions; inverse order; system of nonlinear differential equations; anaerobic digestion.

\section{Introduction}

Anaerobic digestion (AD) is a microbial fermentation in the absence of oxygen results in a mixture of gases (mainly methane and carbon dioxide), known as "biogas" and an aqueous or "sludge" suspension containing the microorganisms responsible for degradation of organic matter. The raw material used primarily to be subjected to this treatment is any residual biomass that has a high moisture content, such as food scraps, leftover leaves and herbs to clean up a garden or orchard, livestock waste, sludge treatment plants urban wastewater and domestic sewage and industrial.

In practice, engineering becomes accustomed to consider three stages for solid waste or sludge (hydrolysis, acidogenic, methanogenic) and two for liquid waste (acidogenic and methanogenic) [1].

We consider the following system of nonlinear ordinary differential equations for the process $\mathrm{AD}[2]$ :

Balance of biomass

$$
\begin{array}{lll}
\frac{d X_{1}}{d t}=\left(\mu_{1}\left(S_{1}\right)-\alpha D\right) & X_{1} & (\text { acidogenic }) \\
\frac{d X_{2}}{d t}=\left(\mu_{2}\left(S_{2}\right)-\alpha D\right) & X_{2} & \text { (metanogenic) }
\end{array}
$$

Balance of substrates

$$
\begin{aligned}
& \frac{d S_{1}}{d t}=D\left(S_{1 i n}-S_{1}\right)-k_{1} \mu_{1}\left(S_{1}\right) X_{1} \quad \text { (acidogenic) } \\
& \frac{d S_{2}}{d t}=D\left(S_{2 i n}-S_{2}\right)+k_{2} \mu_{1}\left(S_{1}\right) X_{1}-k_{3} \mu_{2}\left(S_{2}\right) X_{2} \quad \text { (metanogenic) }
\end{aligned}
$$


Balance of alkalinity

$$
\frac{d A}{d t}=D\left(A_{\text {in }}-A\right)
$$

Carbon rate of change

$$
\frac{d C}{d t}=D\left(C_{i n}-C\right)+k_{4} \mu_{1}\left(S_{1}\right) X_{1}+k_{5} \mu_{2}\left(S_{2}\right) X_{2}-K_{L_{a}}\left[C+S_{2}-A-K_{H} P_{C}\right] .
$$

The expression $K_{L} a\left(C-K_{H} P_{C}\right)$ describes the molar flow rate of inorganic carbon from its liquid phase to its gas phase and the product $K_{H} P_{C}$ determines the concentration of dissolved oxygen in $C$.

Net rate of methane production

$$
\frac{d F_{M}}{d t}=k_{6} \mu_{2}\left(S_{2}\right) X_{2}
$$

The kinetic comportment is nonlinear and occurs because of reaction rates, which are given by: Monod kinetics $\mu_{1}\left(S_{1}\right)=\mu_{1 \max } \frac{S_{1}}{S_{1}+K_{S_{1}}}$ and Haldane kinetics $\mu_{2}\left(S_{2}\right)=$ $\mu_{2 \max } \frac{S_{2}}{\frac{S_{2}^{2}}{K_{I 2}}+S_{2}+K_{S_{2}}}$. Bacterial rate represents yield related to both bioprocesses.

In this case the variables are:

$$
\begin{aligned}
S_{1} & :=\text { Organic substrate concentration }[\mathrm{g} / \mathrm{l}] \\
X_{1} & :=\text { Concentration of acidogenic bacteria }[\mathrm{g} / \mathrm{l}] \\
S_{2} & :=\text { Volatile fatty acids concentration }[\mathrm{mmol} / \mathrm{l}] \\
X_{2} & :=\text { Concentration of methanogenic bacteria }[\mathrm{g} / \mathrm{l}] \\
A & :=\text { Concentration of alkalinity }[\mathrm{mmol} / \mathrm{l}] \\
C & :=\text { Total inorganic carbon concentration }[\mathrm{mmol} / \mathrm{l}] \\
F_{M} & :=\text { Methane concentration }\left[\mathrm{mmol} / \mathrm{l} \mathrm{d}^{-1}\right]
\end{aligned}
$$

The main objective is to build lower-upper solutions for the system formed by equations (1) and (3) in reverse order with respect to a part of variables with initial conditions on a given observation interval [3].

The corresponding equations:

$$
\begin{aligned}
& u^{\prime}=f(x, u, v) \quad \text { in } \quad I, \\
& v^{\prime}=g(x, u, v) \quad \text { in } \quad I,
\end{aligned}
$$

where $I=[a, b], u=X_{1}, v=S_{1}$. Note that the definition of lower-upper solution (8) depends greatly on the properties of monotony of $f$ and $g$. Therefore following notation of C.V. Pao in [4] and new results presented in [5], we can classify (8) according to their relative monotony, as follows:

1. Quasi-monotone systems: $f$ and $g$ are nondecreasing in $v$ and $u$, respectively or $f$ and $g$ are nonincreasing in $v$ and $u$, respectively. 
2. Mixed quasi-monotone systems: either, $f$ is nondecreasing in $v$ and $g$ is nonincreasing in $u$, or vice versa.

3. Nonquasi-monotone systems: the system does not fall in any of the previous cases. in $I$

Case 1 implies the existence of lower $\left(u_{*}, v_{*}\right)$ and upper $\left(u^{*}, v^{*}\right)$ solution with ordering

$$
u_{*} \leq u^{*}, \quad v_{*} \leq v^{*} .
$$

It is impossible to enforce quasi-monotonicity by a simple transformation for Case 2. Case 3 requires some regularity conditions imposed on $f$ and $g$.

In the above system, the usual order $\left(X_{10} \leq X_{1}^{0}\right)$ is considered for the lower and upper solutions. For the variable $S_{1}$ the situation is different because of the opposite case $S_{1}^{0} \leq S_{10}$. We consider the nonlinear equation [6]

$$
u^{\prime}(t)=f(t, u(t)), \quad t \in I=[0, T], \quad T>0
$$

satisfying the condition [6]

$$
g(u(0), u(T))=0,
$$

where $f: I \times R \rightarrow R$ and $g: R^{2} \rightarrow R$ are continuous functions. If $g(x, y)=x-c$ with $c \in R$, then (10) is the initial condition

$$
u(0)=c .
$$

Definition 1. [6]

- $\omega \in C^{1}(I)$ is a lower solution to (9) if

$$
\omega^{\prime}(t) \leq f(t, \omega(t)), \quad t \in I
$$

and

$$
\omega(t) \leq \beta(t), \quad t \in I
$$

- $\beta \in C^{1}(I)$ is upper solution to (9) if

$$
\beta^{\prime}(t) \geq f(t, \beta(t)), \quad t \in I
$$

and

$$
\beta(t) \leq \omega(t), \quad t \in I
$$

For $u, v \in C(I), u \leq v$ define the set

$$
[u, v]=\{\forall w \in C(I): u(t) \leq w(t) \leq v(t), \text { with } t \in I\} .
$$

Definition 2. [6] We say that $\omega, \beta \in C^{1}(I)$ are lower and upper coupled solutions to problem (9), (10) in direct order if $\omega$ is a lower solution and $\beta$ is an upper solution to equation (9), with condition (11) and

$$
\max \{g(\omega(0), \omega(T)), g(\beta(0), \beta(T))\} \leq 0 \leq \min \{g(\beta(0), \beta(T)), g(\beta(0), \omega(T))\} .
$$


Definition 3. [6] We say that $\omega, \beta \in C^{1}(I)$ are lower and upper coupled solutions to problem (9), (10) in inverse order if $\omega$ is a lower solution and $\beta$ is an upper solution to equation (9), with condition (12) and

$$
\max \{g(\omega(0), \omega(T)), g(\beta(0), \omega(T))\} \leq 0 \leq \min \{g(\beta(0), \beta(T)), g(\omega(0), \beta(T))\} .
$$

Theorem 1. [6] It is assumed that $\omega, \beta$ are lower and upper solutions coupled in inverse order to problem (9), (10). Additionally it is assumed that the functions

$$
h_{\omega}(x):=g(x, \omega(T)), \quad h_{\beta}:=g(x, \beta(T))
$$

are monotonic (both non-increasing or non-decreasing) in $[\beta(0), \omega(0)]$. Then there exists at least one solution of problem $(1)-(3)$ in $[\beta, \omega]$.

The inverse order of lower and upper solutions for system (1) - (7) were not previously considered. The outline of this paper comprises the following stages: definition of trivial solutions for the complete system, construction of lower and upper solutions for a subsystem, study and formulation of the corresponding theorem for the existence of lower and upper solutions.

Definition 4. A trivial solution of system (1) - (7) has the form

$$
\begin{aligned}
& E_{1}\left(S_{1 i n}, 0\right), E_{2}\left(S_{1 i n}, 0, S_{2 i n}, 0\right), E_{3}\left(0,0, S_{2 i n}\right) \\
& E_{4}\left(S_{1 i n}, 0, S_{2 i n}, 0, A_{i n}\right), E_{5}\left(A_{i n}\right), E_{6}\left(0, S_{2 i n}, 0\right)
\end{aligned}
$$

where

$$
\begin{gathered}
X_{1}=0, X_{2}=0, S_{1}=S_{1 i n} \\
S_{2}=S_{2 i n}, A=A_{\text {in }}, C=C_{i n}, F_{M}=0
\end{gathered}
$$

We do not consider other possibilities of trivial solutions in this document. A similar approach can be found in [7].

\section{Main Results}

\subsection{Lower and Upper Solutions to the Initial Value Problem}

We are interested in solutions of nonlinear system with initial conditions, which models the dynamics of biomass and substrate in the acidogenic.

$$
\begin{array}{lr}
\frac{d X_{1}}{d t}=\left(\mu_{1_{\max }} \frac{S_{1}}{S_{1}+K_{S_{1}}}-\alpha D\right) X_{1} & \triangleq F\left(t, X_{1}(t), S_{1}(t)\right), \\
\frac{d S_{1}}{d t}=D\left(S_{1 \text { in }}-S_{1}\right)-k_{1} \mu_{1_{\max } \frac{S_{1}}{S_{1}+K_{S_{1}}} X_{1}} & \triangleq G\left(t, X_{1}(t), S_{1}(t)\right), \\
& X_{1}(0)=c_{1}, \\
S_{1}(0)=c_{2} .
\end{array}
$$

Where $t \in[0, T]=I$, with $T>0$ and $F, G$ are functions of class $C^{0}(I)=C(I)$, i.e., continuous functions in $I$. 
A. Define

$$
f\left(S_{1}\right)=\mu_{1_{\max }} \frac{S_{1}}{S_{1}+K_{S_{1}}}-\alpha D \quad \text { and } \quad g\left(S_{1}\right)=\mu_{1_{\max }} \frac{S_{1}}{S_{1}+K_{S_{1}}} .
$$

The function $g\left(S_{1}\right)=\mu_{1_{\max }} \frac{S_{1}}{S_{1}+K_{S_{1}}}$ with $\mu_{1_{\max }}, K_{S_{1}}>0$ is a monotonically increasing function such that $g\left(S_{1}\right) \longrightarrow \mu_{1_{\max }}$ as $S_{1} \longrightarrow \infty$.

If $\mu_{1_{\max }} \frac{S_{1}}{S_{1}+K_{S_{1}}}-\alpha D \geq 0$ then it can be proved that $f\left(S_{1}\right)=O\left(g\left(S_{1}\right)\right)$, i.e.,

$$
\begin{aligned}
& \forall\left(S_{1}\right) \exists(c>0) \quad \text { such that }\left\|f\left(S_{1}\right)\right\| \leq c\left\|g\left(S_{1}\right)\right\| . \\
0 & \leq \mu_{1_{\max }} \frac{S_{1}}{S_{1}+K_{S_{1}}}-\alpha D \leq \mu_{1_{\max }} \frac{S_{1}}{S_{1}+K_{S_{1}}} \\
\Longrightarrow & \left\|\mu_{1_{\max }} \frac{S_{1}}{S_{1}+K_{S_{1}}}-\alpha D\right\| \leq 1 \cdot\left\|\mu_{1_{\max }} \frac{S_{1}}{S_{1}+K_{S_{1}}}\right\| \\
\Longrightarrow & \left\|f\left(S_{1}\right)\right\| \leq c\left\|g\left(S_{1}\right)\right\| \\
\Longrightarrow & \left\|\mu_{1_{\max }} \frac{S_{1}}{S_{1}+K_{S_{1}}}-\alpha D\right\| \leq K .
\end{aligned}
$$

If $\mu_{1 \max } \frac{S_{1}}{S_{1}+K_{S_{1}}}-\alpha D<0$ then $X_{1} \longrightarrow 0$ and

$$
\left\|\mu_{1_{\max }} \frac{S_{1}}{S_{1}+K_{S_{1}}}-\alpha D\right\|\left\|X_{1}\right\| \leq K
$$

Condition A shows that the norm

$$
\left\|\mu_{1_{\max }} \frac{S_{1}}{S_{1}+K_{S_{1}}}-\alpha D\right\|
$$

is bounded.

We define the lower-upper solution in inverse order with respect to the variable $S_{1}$ and in direct order for $X_{1}$ as follows:

Definition 5. [Lower-upper solution] A pair $\left[\left(X_{10}, S_{10}\right),\left(X_{1}^{0}, S_{1}^{0}\right)\right]$ is called

(a) a lower-upper solution of problem (14), if the following conditions are satisfied

$$
\begin{array}{cll}
\quad\left(X_{10}, S_{10}\right) \in C^{1}(I), \quad\left(X_{1}^{0}, S_{1}^{0}\right) \in C^{1}(I), & t \in I \\
\dot{X}_{10}-F\left(t, X_{10}, S_{1}\right) \leq 0 & & \text { (lower) } \\
\dot{X}_{1}{ }^{0}-F\left(t, X_{1}^{0}, S_{1}\right) \geq 0 \text { in } & I, \quad \forall S_{1} \in\left[S_{1}^{0}, S_{10}\right], & \text { (upper) } \\
\dot{S}_{10}-G\left(t, X_{1}, S_{10}\right) \leq 0 & & \text { (lower in inverse order) } \\
\dot{S}_{1}^{0}-G\left(t, X_{1}, S_{1}^{0}\right) \geq 0 \text { in } \quad I, \quad \forall X_{1} \in\left[X_{10}, X_{1}^{0}\right] & \text { (upper in inverse order) } \\
\quad \text { with } & \\
X_{10}(0) \leq c_{2} \leq X_{1}^{0}(0), \quad S_{1}^{0}(0) \leq c_{1} \leq S_{10}(0) & \text { (initial conditions); }
\end{array}
$$


(b) a lower-lower solution of problem (14), if the following conditions are satisfied

$$
\begin{aligned}
& \dot{X}_{10}-F\left(t, X_{10}, S_{10}\right) \leq 0 \text { in } I \\
& \dot{S}_{0}-G\left(t, X_{10}, S_{10}\right) \leq 0 \text { in } I
\end{aligned}
$$

with $S_{1}^{0}(0) \leq c_{1} \leq S_{10}(0)$;

(c) an upper-upper solution of problem (14), if the following conditions are satisfied

$$
\begin{aligned}
& \dot{X}_{1}^{0}-F\left(t, X_{1}^{0}, S_{1}^{0}\right) \geq 0 \quad \text { in } I, \\
& \dot{S}_{1}^{0}-G\left(t, X_{1}^{0}, S_{1}^{0}\right) \geq 0 \quad \text { in } I
\end{aligned}
$$

with $X_{10} \leq X_{1}^{0}, \quad S_{1}^{0} \leq S_{10}$ in $I$.

Definition 6. The functions $\Phi\left(t, t_{S_{1 i}}, \mu_{1 \max }, K_{S_{1}}, D, \alpha\right), \Phi_{1}\left(t, t_{X_{1 i}}, D, S_{1 \text { in }}, k_{1}, \mu_{1 \max }, K_{S_{1}}\right)$ are called semitrivial solutions of problem (14)

if $\Phi\left(t, t_{S_{1 i}}, \mu_{1 \max }, K_{S_{1}}, D, \alpha\right)$ is a solution of the $O D E$ :

$$
\dot{X}_{1}=\left(\mu_{1 \max } \frac{t_{S_{1 i}}}{t_{S_{1 i}}+K_{S_{1}}}-\alpha D\right) X_{1}
$$

and $\Phi_{1}\left(t, t_{X_{1 i}}, D, S_{1 i n}, k_{1}, \mu_{1 \max }, K_{S_{1}}, \alpha\right)$ is a solution of the following ODE:

$$
\dot{S}_{1}=D\left(S_{1 i n}-S_{1}\right)+k_{1} \mu_{1 \max } \frac{S_{1}}{S_{1}+K_{S_{1}}} t_{X_{1 i}}
$$

Here $t_{S_{1 i}}, i=1,2,3$ and $t_{X_{1 i}}, i=1,2,3$ are the indicators of semitrivial solutions $\Phi\left(t, t_{S_{1 i}}, \mu_{1 \max }, K_{S_{1}}, D, \alpha\right)$ and $\Phi_{1}\left(t, t_{X_{1 i}}, D, S_{i n}, k_{1}, \mu_{1 \max }, K_{S_{1}}\right)$ respectively, defined by the following way:

If $S_{1}=S_{1 i n}$, then $t_{S_{11}}=S_{1 i n}$;

If $S_{1}=S_{1}^{0}$, then $t_{S_{12}}=S_{1}^{0}$ is an upper solution of problem (17);

If $S_{1}=S_{10}$, then $t_{S_{13}}=S_{10}$ is a lower solution of problem (17);

If $X_{1}=0$, then $t_{X_{11}}=0$;

If $X_{1}=X_{1}^{0}$, then $t_{X_{12}}=X_{1}^{0}$ is an upper solution of problem (16);

If $X_{1}=X_{10}$, then $t_{X_{13}}=X_{10}$ is a lower solution of problem (16).

From Definition 6, we obtain different types of semitriviales solutions of system (14):

$$
\begin{aligned}
\dot{X}_{1} & =\left(\mu_{1 \max } \frac{S_{1 i n}}{S_{1 i n}+K_{S_{1}}}-\alpha D\right) X_{1}, \\
\dot{S}_{1} & =D\left(S_{1 \text { in }}-S_{1}\right)
\end{aligned}
$$

for $\left(X_{1}, S_{1}\right)$ with ordering of lower and upper solution

$$
X_{10}(t) \leq X_{1}^{0}(t), \quad S_{1}^{0}(t) \leq S_{10}(t) .
$$

Theorem 2. Assume that condition $\mathbf{A}$ is fulfilled and there exists a pair $\left(X_{10}, S_{1}^{0}\right)$, $\left(X_{1}^{0}, S_{10}\right)$ of lower-upper solutions of (14). Then there exists at least a solution of 
semitrivial equations (16), (17) and there exists a solution $\left(X_{1}, S_{1}\right)$ of system (14) such that

$$
\begin{aligned}
& X_{10}(t) \leq X_{1}(t) \leq X_{1}^{0}(t), \quad t \in I \\
& S_{1}^{0}(t) \leq S_{1}(t) \leq S_{10}(t), \quad t \in I .
\end{aligned}
$$

Proof. It is divided into two steps. First, we consider a modified problem and show that any solution of this problem is also a solution of the original problem and that it is between $X_{10}$ and $X_{1}^{0}, S_{1}^{0}$ and $S_{10}$ (reverse order) by means of differential inequalities. Second, a direct application of the Banach fixed point theorem shows that equations (16), (17) for the semitrivial solutions have at least one solution. Last result guarantees the existence of solution $\left(X_{1}, S_{1}\right)$ to system (14).

Step 1. Introduce the space

$$
K \equiv\left[X_{10}, X_{1}^{0}\right] \times\left[S_{1}^{0}, S_{10}\right] \subset E \equiv C(I) \times C(I) .
$$

$K$ is a bounded closed convex set in $E$. Now, given $\left(X_{1}, S_{1}\right)$, define the functions:

$$
\begin{aligned}
& f_{\left(X_{1}, S_{1}\right)}(t, u)=\left\{\begin{array}{lll}
F\left(t, X_{1}^{0}\right)+X_{1}^{0} & \text { if } \quad X_{1}^{0}<u, \\
F(t, u)+u & \text { if } \quad X_{10} \leq u \leq X_{1}^{0}, \\
F\left(t, X_{10}\right) X_{10} & \text { if } u<X_{10},
\end{array}\right. \\
& g_{\left(X_{1}, S_{1}\right)}(t, v)=\left\{\begin{array}{lll}
G\left(t, S_{1}^{0}\right)-S_{1}^{0} & \text { if } \quad S_{1}^{0}>v, \\
G(t, v)-v & \text { if } \quad S_{1}^{0} \leq v \leq S_{10}, \\
G\left(t, S_{10}\right)-S_{10} & \text { if } v>S_{10} .
\end{array}\right.
\end{aligned}
$$

Define the mapping $T: K \rightarrow E$ by $T\left(X_{1}, S_{1}\right)=(u, v)$, where $u$ and $v$ are the solutions, respectively, of the modified problems

$$
\begin{gathered}
(I) \quad u^{\prime}(t)+u(t)=f_{\left(X_{1}, S_{1}\right)}(t, u(t)), \\
u(0)=c_{1}, \\
(I I) \quad v^{\prime}(t)-v(t)=g_{\left(X_{1}, S_{1}\right)}(t, v(t)), \\
v(0)=c_{2}
\end{gathered}
$$

that and reduced to $(14)$, when $(t, u(t)) \times(t, v(t)) \in E$. We claim that any solution $u$ of Eq. (I) is such that $X_{10}(t) \leq u(t) \leq X_{1}^{0}(t)$ for all $t \in I$, so that it is also a solution of (14a).

We shall prove that $u(t) \leq X_{1}^{0}(t)$ for all $t \in I$. The proof of the other inequality is similar.

If $u$ is a solution of (I), then, by (20), for some $t \in I$ such that $\left(u-X_{1}^{0}\right)(t)>0$, one has

$$
u^{\prime}(t)=F\left(t, X_{1}^{0}\right)+u(t)-X_{1}^{0}>\dot{X}_{1}^{0}
$$

so that

$$
\left(u-X_{1}^{0}\right)^{\prime}(t)>0
$$


for some $t \in I$ such that $\left(u-X_{1}^{0}\right)(t)>0$. Therefore $u(t)>X_{1}^{0}$ for all $t \in I$, but this can not happen because it contradicts the definition of upper solution $u(t) \leq X_{1}^{0}$. Hence, there exists $t_{1} \in I$ such that $\left(u-X_{1}^{0}\right)\left(t_{1}\right) \leq 0$.

We shall prove that $v(t) \geq S_{1}^{0}(t)$ for all $t \in I$. The proof of the other inequality is similar.

If $v$ is a solution of (II), then, by (21), for some $t \in I$ such that $\left(v-S_{1}^{0}\right)(t)<0$, one has

$$
v^{\prime}(t)=G\left(t, S_{1}^{0}\right)+v(t)+S_{1}^{0}<\dot{S}_{1}^{0}
$$

so that

$$
\left(v-S_{1}^{0}\right)^{\prime}(t)<0
$$

for some $t \in I$ such that $\left(v-S_{1}^{0}\right)(t)<0$. Therefore $v(t)<S_{1}^{0}$ for all $t \in I$, but this can not happen because it contradicts the definition $v(t) \geq S_{1}^{0}$. Hence, there exists $t_{2} \in I$ such that $\left(v-S_{1}^{0}\right)\left(t_{2}\right) \geq 0$.

Step 2. Consider equations (16), (17) for semitrivial solutions. Apply the Banach fixed point theorem as following:

Define $T_{1}: C(I) \longrightarrow C(I)$ by

$$
T_{1} X_{10}(t):=c_{1}+\int_{0}^{t}\left[\mu_{1_{\max }} \frac{S_{1}^{0}(s)}{S_{1}^{0}(s)+K_{S_{1}}}-\alpha D\right] \quad X_{10}(s) d s, \quad X_{10} \in C(I) .
$$

If $\left\|X_{10}\right\| \leq M_{1}$ then

$$
\left|T_{1} X_{10}-T_{1} X_{10}^{*}\right| \leq\left\|\mu_{1_{\max }} \frac{S_{1}^{0}}{S_{1}^{0}+K_{S_{1}}}-\alpha D\right\|\left\|X_{10}-X_{10}^{*}\right\| .
$$

The norm is bounded due to condition $\mathbf{A}$

$$
\left\|\mu_{1_{\max }} \frac{S_{1}^{0}}{S_{1}^{0}+K_{S_{1}}}-\alpha D\right\| \leq K_{1}
$$

So

$$
\left|T_{1} X_{10}-T_{1} X_{10}^{*}\right| \leq K_{1}\left\|X_{10}-X_{10}^{*}\right\| \text { for every } K_{1}>0
$$

Now define $T_{2}: C(I) \longrightarrow C(I)$ by

$$
T_{2} X_{1}^{0}(t):=c_{1}+\int_{0}^{t}\left[\mu_{1_{\max }} \frac{S_{1}^{0}(s)}{S_{1}^{0}(s)+K_{S_{1}}}-\alpha D\right] X_{1}^{0}(s) d s, \quad X_{1}^{0} \in C(I) .
$$

If $\left\|X_{1}^{0}\right\| \leq M_{2}$ then

$$
\left|T_{2} X_{1}^{0}-T_{2} X_{1}^{0^{*}}\right| \leq\left\|\mu_{1_{\max }} \frac{S_{1}^{0}}{S_{1}^{0}+K_{S_{1}}}-\alpha D\right\|\left\|X_{1}^{0}-X_{1}^{0^{*}}\right\| .
$$

The norm is bounded due to condition $\mathbf{A}$

$$
\left|T_{2} X_{1}^{0}-T_{2} X_{1}^{0^{*}}\right| \leq K_{1}\left\|X_{1}^{0}-X_{1}^{0^{*}}\right\| \text { for every } K_{1}>0 .
$$


Consequently $T_{1}, T_{2}$ are contractive mappings from $\left\{X_{10}, X_{1}^{0} \in C(I),\left\|X_{10}\right\| \leq M_{1}\right.$, $\left.\left\|X_{1}^{0}\right\| \leq M_{2}\right\}$ for every $M_{1}>1$ and for every $M_{2}>1$. Then $T_{1}$ and $T_{2}$ have a unique fixed point in $C(I)$.

Similarly, define $T_{3}: C(I) \longrightarrow C(I)$ by

$$
T_{3} S_{1}^{0}(t):=c_{2}+\int_{0}^{t}\left[D\left(S_{1 \text { in }}-S_{1}^{0}(s)\right)-k_{1} \mu_{1_{\max }} \frac{S_{1}^{0}(s)}{S_{1}^{0}(s)+K_{S_{1}}} X_{10}(s)\right] S_{1}^{0}(s) d s, S_{1}^{0} \in C(I) .
$$

If $\left\|S_{1}^{0}\right\| \leq N_{1}$ then

$$
\left|T_{3} S_{1}^{0}-T_{3} S_{1}^{0^{*}}\right| \leq\left\|D S_{1 \text { in }}-\left[D+k_{1} \mu_{1_{\max }} \frac{1}{S_{1}^{0}+K_{S_{1}}} X_{10}\right] S_{1}^{0}\right\|\left\|S_{1}^{0}-S_{1}^{0^{*}}\right\| .
$$

Estimate the norm

$$
\left\|D\left(S_{1 i n}-S_{1}^{0}\right)-\frac{k_{1} \mu_{1_{\max }} S_{1}^{0}}{S_{1}^{0}+K_{S_{1}}} X_{10}\right\| .
$$

As $\left\|X_{10}\right\| \leq M_{1}, \forall S_{1}^{0}, S_{1}^{0^{*}} \in C(I)$

$$
\begin{aligned}
& D\left(S_{1 i n}-S_{1}^{0}\right)-\frac{k_{1} \mu_{1_{\max }} S_{1}^{0}}{S_{1}^{0}+K_{S_{1}}} X_{10}-\left(D\left(S_{1 i n}-S_{1}^{0^{*}}\right)-\frac{k_{1} \mu_{1_{\max }} S_{1}^{0^{*}}}{S_{1}^{0^{*}}+K_{S_{1}}} X_{10}\right)= \\
& =D\left(S_{1}^{0^{*}}-S_{1}^{0}\right)+k_{1} \mu_{1_{\max }}\left(\frac{S_{1}^{0^{*}}}{S_{1}^{0^{*}}+K_{S_{1}}}-\frac{S_{1}^{0}}{S_{1}^{0}+K_{S_{1}}}\right) X_{10}
\end{aligned}
$$

then

$$
\begin{aligned}
& \left\|D\left(S_{1}^{0^{*}}-S_{1}^{0}\right)+k_{1} \mu_{1_{\max }}\left(\frac{S_{1}^{0^{*}}-S_{1}^{0}}{\left(S_{1}^{0^{*}}+K_{S_{1}}\right)\left(S_{1}^{0}+K_{S_{1}}\right)}\right) X_{10}\right\| \leq \\
& \leq\left\|D\left(S_{1}^{0^{*}}-S_{1}^{0}\right)\right\|+\left|k_{1} \mu_{1_{\max }}\right|\left\|\frac{S_{1}^{0^{*}}-S_{1}^{0}}{\left(S_{1}^{0^{*}}+K_{S_{1}}\right)\left(S_{1}^{0}+K_{S_{1}}\right)}\right\|\left\|X_{10}\right\|= \\
& =\left\|D\left(S_{1}^{0^{*}}-S_{1}^{0}\right)\right\|+\left|k_{1} \mu_{1_{\max }}\right|\left\|\frac{1}{\left(S_{1}^{0^{*}}+K_{S_{1}}\right)\left(S_{1}^{0}+K_{S_{1}}\right)}\right\|\left\|S_{1}^{0^{*}}-S_{1}^{0}\right\|\left\|X_{10}\right\| .
\end{aligned}
$$

Now estimate the norm

$$
\left\|\frac{S_{1}^{0^{*}}-S_{1}^{0}}{\left(S_{1}^{0^{*}}+K_{S_{1}}\right)\left(S_{1}^{0}+K_{S_{1}}\right)}\right\|
$$

taking

$$
h\left(S_{1}^{0}\right)=\frac{1}{\left(S_{1}^{0}+K_{S_{1}}\right)\left(S_{1}^{0^{*}}+K_{S_{1}}\right)}
$$

as $S_{1}^{0}, S_{1}^{0^{*}}>0$ and the constant $K_{S_{1}}>0$. Then $h\left(S_{1}^{0}\right)<1$, hence $\left\|h\left(S_{1}^{0}\right)\right\| \leq K_{2}$ so one has

$$
\begin{aligned}
& \left\|D\left(S_{1}^{0^{*}}-S_{1}^{0}\right)+k_{1} \mu_{1_{\max }}\left(\frac{S_{1}^{0^{*}}-S_{1}^{0}}{\left(S_{1}^{0^{*}}+K_{S_{1}}\right)\left(S_{1}^{0}+K_{S_{1}}\right)}\right) X_{10}\right\| \leq \\
& \leq\left\|D\left(S_{1}^{0^{*}}-S_{1}^{0}\right)\right\|+\left|k_{1} \mu_{1_{\max }}\right|\left\|\frac{1}{\left(S_{1}^{0^{*}}+K_{S_{1}}\right)\left(S_{1}^{0}+K_{S_{1}}\right)}\right\|\left\|S_{1}^{0^{*}}-S_{1}^{0}\right\|\left\|X_{10}\right\| \leq \\
& \leq\left(|D|+\left|k_{1} \mu_{1_{\max }} K_{2} M_{1}\right|\right)\left\|S_{1}^{0^{*}}-S_{1}^{0}\right\| \leq\left(K_{3}=\max \left\{|D|,\left|k_{1} \mu_{1_{\max }} K_{2} M_{1}\right|\right\}\right)\left\|S_{1}^{0^{*}}-S_{1}^{0}\right\| .
\end{aligned}
$$


Then $\left\|T_{3} S_{1}^{0}-T_{3} S_{1}^{0^{*}}\right\| \leq K_{3}\left\|S_{1}^{0}-S_{1}^{0^{*}}\right\|$, for every $K_{3}>0$.

Now define $T_{4}: C(I) \longrightarrow C(I)$ by

$T_{4} S_{10}(t):=c_{2}+\int_{0}^{t}\left[D\left(S_{1 i n}-S_{10}(s)\right)-k_{1} \mu_{1 \max } \frac{S_{10}(s)}{S_{10}(s)+K_{S_{1}}} X_{10}(s)\right] S_{10}(s) d s, S_{10} \in C(I)$.

If $\left\|S_{10}\right\| \leq N_{2}$ then

$$
\left|T_{4} S_{10}-T_{4} S_{10}^{*}\right| \leq\left\|D S_{1 i n}-\left[D+k_{1} \mu_{1_{\max }} \frac{1}{S_{10}+K_{S_{1}}} X_{10}\right] S_{10}\right\|\left\|S_{10}-S_{10}^{*}\right\| .
$$

Estimate the norm

$$
\left\|D\left(S_{1 i n}-S_{10}\right)-\frac{k_{1} \mu_{1 \max } S_{10}}{S_{10}+K_{S_{1}}} X_{10}\right\|
$$

As $\left\|X_{10}\right\| \leq M_{1}, \forall S_{10}, S_{10}^{*} \in C(I)$

$$
\begin{aligned}
& D\left(S_{1 i n}-S_{10}\right)-\frac{k_{1} \mu_{1_{\max }} S_{10}}{S_{10}+K_{S_{1}}} X_{10}-\left(D\left(S_{1 i n}-S_{10}^{*}\right)-\frac{k_{1} \mu_{1_{\max }} S_{10}^{*}}{S_{10}^{*}+K_{S_{1}}} X_{10}\right)= \\
& =D\left(S_{10}^{*}-S_{10}\right)+k_{1} \mu_{1_{\max }}\left(\frac{S_{10}^{*}}{S_{10}^{*}+K_{S_{1}}}-\frac{S_{10}}{S_{10}+K_{S_{1}}}\right) X_{10}
\end{aligned}
$$

then

$$
\begin{aligned}
& \left\|D\left(S_{10}^{*}-S_{10}\right)+k_{1} \mu_{1_{\max }}\left(\frac{S_{10}^{*}-S_{10}}{\left(S_{10}^{*}+K_{S_{1}}\right)\left(S_{10}+K_{S_{1}}\right)}\right) X_{10}\right\| \leq \\
& \leq\left\|D\left(S_{10}^{*}-S_{10}\right)\right\|+\left|k_{1} \mu_{1_{\max }}\right|\left\|\frac{S_{10}^{*}-S_{10}}{\left(S_{10}^{*}+K_{S_{1}}\right)\left(S_{10}+K_{S_{1}}\right)}\right\|\left\|X_{10}\right\|= \\
& =\left\|D\left(S_{10}^{*}-S_{10}\right)\right\|+\left|k_{1} \mu_{1_{\max }}\right|\left\|\frac{1}{\left(S_{10}^{*}+K_{S_{1}}\right)\left(S_{10}+K_{S_{1}}\right)}\right\|\left\|S_{10}^{*}-S_{10}\right\|\left\|X_{10}\right\| .
\end{aligned}
$$

Now estimate the norm

$$
\left\|\frac{S_{10}^{*}-S_{10}}{\left(S_{10}^{*}+K_{S_{1}}\right)\left(S_{10}+K_{S_{1}}\right)}\right\|
$$

taking

$$
h\left(S_{10}\right)=\frac{1}{\left(S_{10}+K_{S_{1}}\right)\left(S_{10}^{*}+K_{S_{1}}\right)} .
$$

As $S_{10}, S_{10}^{*}>0$ and the constant $K_{S_{1}}>0$ then $h\left(S_{10}\right)<1$, then $\left\|h\left(S_{10}\right)\right\| \leq K_{4}$. So one has

$$
\begin{aligned}
& \left\|D\left(S_{10}^{*}-S_{10}\right)+k_{1} \mu_{1_{\max }}\left(\frac{S_{10}^{*}-S_{10}}{\left(S_{10}^{*}+K_{S_{1}}\right)\left(S_{10}+K_{S_{1}}\right)}\right) X_{10}\right\| \leq \\
& \leq\left\|D\left(S_{10}^{*}-S_{10}\right)\right\|+\left|k_{1} \mu_{1_{\max }}\right|\left\|\frac{1}{\left(S_{10}^{*}+K_{S_{1}}\right)\left(S_{10}+K_{S_{1}}\right)}\right\|\left\|S_{10}^{*}-S_{10}\right\|\left\|X_{10}\right\| \leq \\
& \leq\left(|D|+\left|k_{1} \mu_{1_{\max }} K_{4} M_{1}\right|\right)\left\|S_{10}^{*}-S_{10}\right\| \leq\left(K_{5}=\max \left\{|D|,\left|k_{1} \mu_{1_{\max }} K_{4} M_{1}\right|\right\}\right)\left\|S_{10}^{*}-S_{10}\right\| .
\end{aligned}
$$

So $\left\|T_{4} S_{10}-T_{4} S_{10}^{*}\right\| \leq K_{5}\left\|S_{10}-S_{10}^{*}\right\|$ for every $K_{5}>0$. 
Consequently $T_{3}, T_{4}$ are contractive mappings from $\left\{S_{1}^{0}, S_{10} \in C(I),\left\|S_{1}^{0}\right\| \leq N_{1}\right.$, $\left.\left\|S_{10}\right\| \leq N_{2}\right\}$ for every $N_{1}>1$ and for every $N_{2}>1$. Then $T_{3}$ and $T_{4}$ have a unique fixed point in $C(I)$.

We have proved that every mapping of $T_{1}, T_{2}, T_{3}, T_{4}$ has a unique fixed point in $C(I)$, this guarantees the existence of solutions $S_{10}, S_{1}^{0}, X_{10}, X_{1}^{0}$. This is sufficient to guarantee the existence of solutions $X_{1}$ and $S_{1}$ such that $X_{10} \leq X_{1} \leq X_{1}^{0}$ and $S_{1}^{0} \leq S_{1} \leq S_{10}$.

\subsection{Semitrivial Solutions $S_{1}$ and $X_{1}$}

Consider in system (14) the trivial solution $E_{1}\left(0, S_{1 i n}\right)$ defined by $(13)$ and search an analytical solution of linear equation (15d)

$$
\begin{gathered}
\frac{d S_{1}}{d t}-D\left(S_{1 i n}-S_{1}\right)=0 \\
S_{1}=S_{1 i n}-\left[S_{1 i n}-S_{1}(0)\right] \exp (-D t) .
\end{gathered}
$$

When $S_{1 \text { in }}>S_{1}(0)$ a graph of solution at $t \rightarrow \infty$ asymptotically decreases to a value $S_{1 \text { in }}$. And for $S_{1 \text { in }}<S_{1}(0)$ a graph of solution at $t \rightarrow \infty$ asymptotically increases to a value $S_{1 i n}$. However, we wish to demonstrate the method of upper and lower solutions. We take $\epsilon>0$, consider let the solution

$$
S_{1}=S_{1 i n}-\left[S_{1 i n}-S_{1}(0)\right] \exp (-D t)+\epsilon .
$$

Thus

$$
\begin{gathered}
\frac{d S_{1}}{d t}-D\left(S_{1 i n}-S_{1}\right) \geq 0 . \\
D\left(S_{1 i n}-S_{1}\right) \exp (-D t)-D\left(S_{1 i n}-S_{1}\right) \exp (-D t)+D \epsilon \geq 0 .
\end{gathered}
$$

Then $D \epsilon \geq 0$ for $D>0$ and solution $S_{1}=S_{1}^{0}$ is a upper solution of (18b). If $\epsilon<0$, then $S_{10}$ is a lower solution of (18b).

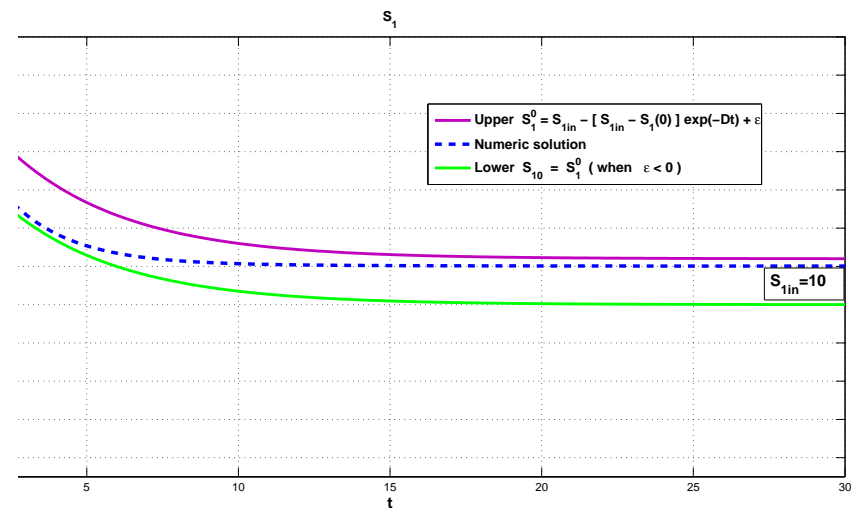

Fig. 1. Tending of a graph to $S_{1 i n}$ as $t \rightarrow \infty$. The parameters for simulation from [2]

Fig. 1 shows that the solution tends to the value $S_{1 \text { in }}$ as $t \rightarrow \infty$. In the process, this represents that bacteria feed on the substrate $S_{1}$ over time. 
Table

The solution to $S_{1}^{0}$

\begin{tabular}{|l|l|l|l|}
\hline Parameter & Value & Units & SD \\
\hline$S_{1}(0)$ & 5 & {$[\mathrm{~g} / \mathrm{l}]$} & \\
\hline$D$ & 0,395 & {$\left[\mathrm{~d}^{-1}\right]$} & 0,135 \\
\hline$S_{1 \text { in }}$ & 10 & {$[\mathrm{~g} / \mathrm{l}]$} & 6,4 \\
\hline
\end{tabular}

Now we look for a semi-trivial upper-solution $X_{1}^{0}$ for equations (15b) and (24). From Definition 5

$$
\dot{X}_{1}^{0}-\left(\mu_{1 \max } \frac{S_{1}^{0}}{S_{1}^{0}+K_{S_{1}}}-\alpha D\right) X_{1}^{0} \geq 0 .
$$

Taking (16) and (24) in (15b), with $c_{8}=S_{1 \text { in }}-S_{1}(0)$ we obtain

$$
\Longrightarrow \quad \dot{X}_{1}^{0}-\left(\mu_{1 \max } \frac{S_{1 i n}-c_{8} \exp (-D t)}{S_{1 i n}-c_{8} \exp (-D t)+K_{S_{1}}}-\alpha D\right) X_{1}^{0}=0
$$

then

$$
X_{1}^{0}=c_{9} * \frac{\left[c_{8} \exp (-D t)\left(S_{1 i n}+K_{S_{1}}-c_{8} \exp (-D t)\right)\right]^{\frac{\mu_{1 \max } S_{1 i n}}{D\left(S_{1 i n}+K_{S_{1}}\right)}}}{\left[S_{1 \text { in }}+K_{S_{1}}-c_{8} \exp (-D t)\right]^{\frac{\mu_{1 \max }}{D}}} * \exp (-\alpha D t)
$$

and a graphic representation is Fig. 2 shows that the upper solution $X_{1}^{0}$ presents condition washout.

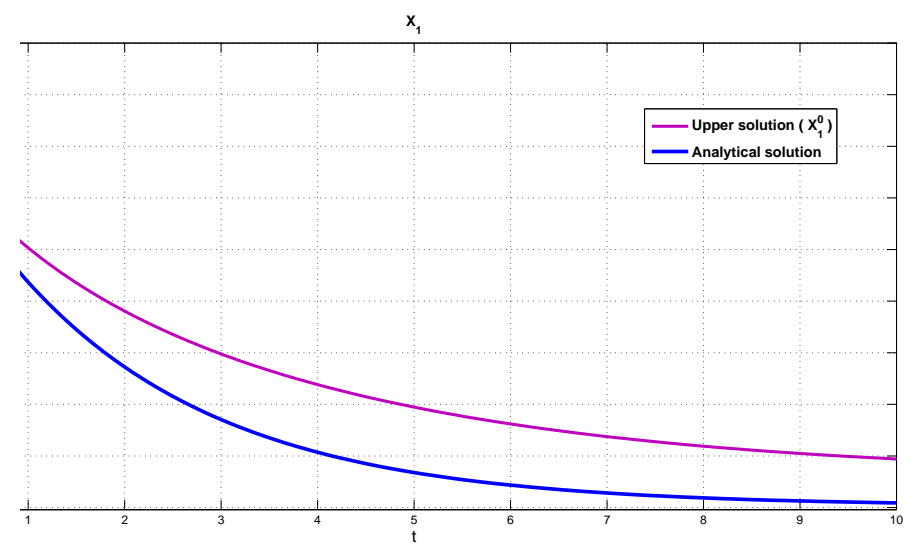

Fig. 2. The graph of the solution $X_{1}$ tending to 0 as $t \rightarrow \infty$. The parameter values are taken from Table, with initial condition $X_{1}(0)=0,5$

\section{Conclusions}

In this paper we presented a study of existence of lower and upper solutions of a system of ordinary differential equations modelling acidogenic stage process of AD. Inverse order of 
lower and upper solutions with respect to variables was considered. We are well aware that this is only the first step in the complete study of the problem. The next step is to consider the V.M. Matrosov comparison principle to explore the global stability of solutions and a complete study of bifurcation (here readers may refer to monographs $[8,9]$ ).

The first author is partially supported by SNI-CONACYT and thanks the University of Ibague in Colombia for their support and also thanks to the doctoral program in mathematics at the Faculty of Mathematics at the University of Veracruz in Mexico.

\section{References}

1. Jewell W. Anaerobic Sewage Treatment. Environmental Science and Technology, 1987, vol. 21, no. 1 , pp. 9-21. DOI: $10.1021 / \mathrm{es} 00155 \mathrm{a} 002$

2. Bernard O., Sadok Z.H., Dochain D., Genovesi A., Steyer J.-P. Dynamical Model Development and Parameter Identification for an Anaerobic Wastewater Treatment Process. Biotechnology and Bioengineering, 2001, vol. 75, no. 4, pp. 424-438. DOI: 10.1002/bit.10036

3. Alcaraz V., Genovesi A., Harmand J., González V., Rapaport A., Steyer J.P. Robust Exponetial Nonlinear Interval Observers for a Class of Lumped Models Useful in Chemical and Biochemical Engineering. Application to a Wastewater Treatment Process. International Workshop on Application of Interval Analysis to Systems and Control, MISC'99, Girona, Spain, 1999, pp. 24-26.

4. Pao C.-V. Nonlinear Parabolic and Elliptic Equations. N.Y., Plenum Press, 1992.

5. Delgado M., Suárez A. Existence of Solutions for Elliptic Systems with Hölder Continuous Nonlinearities. Diferential and Integral Equations, 2000, vol. 13, no. 4, 6, pp. 453-477.

6. Franco D., Nieto J.J., O'Regan D. Upper and Lower Solutions for First Order Problems with Nonlinear Boundary Conditions. Estracta Mathematicae, 2003, vol. 18, no. 2, pp. 153-160

7. Benyahia B., Sari T., Cherki B., Harmand J. Bifurcation and Stability Analysis of a Two Step Model for Monitoring Anaerobic Digestion Processes. Journal of Process Control, 2012, vol. 22, no. 6, pp. 1008-1019. DOI: 10.1016/j.jprocont.2012.04.012

8. Sidorov N., Loginov B., Sinitsyn A., Falaleev M. Lyapunov - Schmidt Methods in Nonlinear Analysis and Applications. Dordrecht, Boston, London, Kluwer Academic Publisher, 2002. 568 p. DOI: $10.1007 / 978-94-017-2122-6$

9. Sviridyuk G.A., Fedorov V.E. Linear Sobolev Type Equations and Degenerate Semigroups of Operators. Utrecht, Boston, Köln, Tokyo, VSP, 2003. 216 p. DOI: 10.1515/9783110915501

10. Lorenzo Y., Obaya M.C. La digestión anaerobia. aspectos teóricos. parte I. ICIDCA. Sobre los Derivados de la Caña de Azúcar, 2005, vol. 39, no. 1, pp. 35-48.

11. McKenna P.-J., Walter W. On the Dirichlet Problem for Elliptic Systems. Applicable Analysis, 1986, no. 21, pp. 207-224. DOI: 10.1080/00036818608839592

12. Salinas E., Muñoz R., Sosa J.-C., López B. Analysis to the Solutions of Abel's Differential Equations of the First Kind under Transformation $y=u(x) z(x)+v(x)$. Applied Mathematical Sciences, 2013, vol. 7, no. 42, pp. 2075-2092.

Received March 11, 2015 
УДК 620.95+517.927

DOI: $10.14529 / \mathrm{mmp} 150205$

\title{
СУЩЕСТВОВАНИЕ НИЖНИХ И ВЕРХНИХ РЕШЕНИЙ В ОБРАТНОМ ПОРЯДКЕ ПО ОТНОШЕНИЮ К ПЕРЕМЕННОЙ В МОДЕЛИ АЦИДОГЕНЕЗА ДЛЯ АНАЭРОБНОГО СБРАЖИВАНИЯ
}

\author{
М.М. Изеэрра, А.В. Синищин
}

Доказано существование верхних и нижних решений в относительно части переменньх в системе нелинейных обыкновенньх дифференциальных уравнений, моделирующих ацидогенез в анаэробном сбраживании в задаче метанообразования. Верхние и нижние решения строятся аналитически, и установлены соответствующие теоремы существования.

Ключевые слова: верхние и нижния решения; обратный порядок; системы нелинейных дифференциальных уравнений; анаэробное сбраживание.

Максимильяно Изеэрра, аспирант школы «Математика», Университет Веракрузана (г. Веракрузана, Мексика), maximiliano.machado@unibague.edu.co.

Александр Синицын, доктор физико-математических наук, профессор факультета «Математика», Национальный университета Боготы, (г. Богота, Колумбия), avsinitsyn@yahoo.com.

Поступила в редакиию 11 марта 2015 г. 